\title{
ТРУД ТРАНСФЕРТНЫЙ И ТОВАРООБМЕННЫЙ
}

\author{
(c) 2021 Лебедев Константин Николаевич \\ доктор экономических наук, профессор, профессор Департамента экономической теории \\ Финансовый университет при Правительстве Российской Федерации, Россия, Москва \\ E-mail: KNLebedev@fa.ru \\ ORCID: https://orcid.org/0000-0002-4846-8097
}

В настоящей статье, написанной в духе теории альтернативных финансов (или теории нефинансовой экономики), выделены типы альтернативных трансфертных и товарообменных систем ресурсообеспечения по признаку фактора производства, охарактеризованы трансфертный и товарообменный типы систем обеспечения фактором производства «труд», обоснована большая эффективность (большая экономичность, большая доступность и меньшая опасность) товарообменного труда по сравнению с трансфертным, показано, что двум этим типам труда соответствуют два типа договора найма труда, используемых в хозяйственно практике - трудовой договор и договор гражданско-правового характера.

Ключевые слова: трансфертный труд, товарообменный труд, трансфертное государство, трудовой договор, договор гражданско-правового характера.

Теория альтернативных финансов (она же теория нефинансовой экономики, несколько изменившая терминологию в связи с принятием широкой трактовки финансов как систем ресурсообеспечения) исходит из того, что все системы ресурсообеспечения (финансы в широком смысле слова) имеют альтернативные трансфертные (традиционные финансы) и товарообменные (альтернативные финансы) подсистемы. При трансфертном обеспечении ресурсы для обслуживания каких-то нужд передаются ресурсополучателю в собственность бесплатно или за неэквивалентную плату, а при товарообменном - на условиях полной оплаты, например традиционный (банковский) потребительский кредит состоит в бесплатной передаче банком денег в собственность клиента для покупки нужной вещи, а исламский потребительский кредит - в покупке нужной клиенту вещи банком и последующей продаже ее клиенту с рассрочкой платежа [5, с. 50]. При этом трансфертному обеспечению ресурсами соответствует отсутствие деятельного участия лица, передающего ресурсы, в судьбе переданных средств, обеспечении их рационального использования и, соответственно, незначительный доход от деятельности по обеспечению ресурсами, тогда как товарообменному обеспечению ресурсами, напротив, соответствует активное участие лица, передающего ресурсы, в обеспечении их эффективного использования и, соответственно, значительно более высокий доход от деятельности по ресурсообеспечению. Так, акционеры классического акционерного общества (АО), т.е. АО с полностью наемным топ-менеджментом, передав свое имущество предприятию (в лице наемного топ-менеджмента), не принимают участия в непосредственном управлении этим имуществом и, соответственно, довольствуются низким и непостоянным дивидендным доходом, тогда как участники полного товарищества, передав свое имущество предприятию, участвуют в повседневном управлении им, получая в связи с этим значительно более высокий доход на вложенный капитал, чем первые. Заметим, что различие в уровне доходности передаваемых ресурсов, вызванное разной степенью участия ресурсодателя в их судьбе, получило отражение в понятиях «пассивный» и «активный доход». Важно отметить, что в теории альтернативных финансов сравнивается удельный доход, т.е. доход на единицу затрат, связанных с его получением. Соответственно, у акционеров классического АО доходы настолько малы, что при всей пассивности их участия в управлении имуществом предприятия доход на рубль их соответствующих затрат будет меньше, чем доход на рубль затрат по управлению имуществом предприятия участников полного товарищества, несмотря на то, что последние расходуют значительно больше энер- 
гии и средств на управление имуществом своего предприятия, чем акционеры классического АО. Соответственно, трансфертные системы с точки зрения ресурсодателей и менее экономичны, т.е. в них рубль дохода обходится дороже, чем в товарообменных системах.

Согласно теории альтернативных финансов, товарообменные системы ресурсообеспечения, т.е. альтернативные финансы, являются более эффективными (более экономичными, более доступными, менее опасными), чем трансфертные системы ресурсообеспечения, т.е. традиционные финансы. Причем товарообменные системы являются более эффективными, чем трансфертные, не только с точки зрения ресурсодателей (выше шла речь о более высокой экономичности товарообменной системы ресурсообеспечения «капитал», т.е. системы наделения предприятия собственными средствами при его учреждении или расширении, по сравнению с трансфертной с точки зрения ресурсодателей), но и с точки зрения ресурсополучателей. Так, получатель традиционного банковского кредита, как правило, переплачивает за нужную ему вещь, получает вещь более низкого качества [1, с. 56], тогда как получатель исламского потребительского кредита застрахован от подобных случаев участием в покупке вещи банка.

Менее эффективное использование ресурсов, полученных по трансфертным сделкам, как раз и объясняется их бесплатным получением или получением за неэквивалентную плату, изза чего ресурсы приобретают в глазах получателей заниженную ценность, и об их рациональном использовании не проявляется должная забота (управление ими становится дурным). Таким образом, более низкий доход ресурсодателей в традиционных финансах объясняется управленческой ленью, и ею же объясняется нерациональное использование соответствующих ресурсов ресурсодателями. Психологи понимают под ленью нежелание или неспособность проявлять активность в каком-либо деле, отказ от преодоления трудностей, бездействие, непроявление упорства и воли в достижении какой-то цели [4]. Соответственно, управленческая лень в рассматриваемом случае представляет собой нежелание или неспособность проявлять активность в управлении полученными или переданными ресурсами, бездействие при необходимости оказывать управляющие воздействия на этот процесс, непроявление упорства и воли для обеспечения адекватного процесса принятия решений об использовании ресурсов.

Теория альтернативных финансов не только отмечает более высокую эффективность альтернативных финансов по сравнению с традиционными, но и наличие в мире тенденции вытеснения альтернативными финансами традиционных финансов, как раз и обусловленную большей эффективностью первых по сравнению со вторыми. Об этом говорит опережающее развитие в последние десятилетия, в частности, того же исламского банкинга по сравнению с традиционным банковским кредитом, лизинга оборудования по сравнению с кредитом на покупку оборудования, кооперативного сектора экономики по сравнению с традиционным сектором, финансирования исследований и разработок из выручки компаний по сравнению с их бюджетным финансированием. При этом теория альтернативных финансов отмечает нелинейность процесса вытеснения традиционных финансов нетрадиционными финансами, которую объясняет сопротивлением, оказываемым первыми развитию вторых, в том числе через различных агентов, которым может выступать, прежде всего, современное государство, близкое к традиционным финансам (финансируемое, главным образом, за счет налогов), т.е. трансфертное государство.

Ранее традиционные и альтернативные финансы рассматривались нами применительно к отраслям традиционных финансов (налоги, бюджет, кредит, капитал, пенсии, страхование, деньги и т.д.), так как теория альтернативных финансов развивалась путем выявления товарообменных альтернатив налогам, бюджету, кредиту и т.д. Однако с самого начала была ясна необходимость группировки систем ресурсообесепечения, прежде всего, по видам передаваемых ресурсов (факторов производства), раз речь идет о системах именно ресурсообеспечения, а не только по исполняемым этими ресурсами функциям (обеспечение временной потребности в средствах, обеспечение в старости, наделение предприятий собственными средствами при учреждении и т.д.). Как известно, все факторы производства (производственные ресурсы) делятся на 3 большие группы - труд, земля и капитал. Отсюда, и системы ресурсообеспечения могут быть разделены на системы обеспечения трудом, землей (природными ресурсами) и капиталом (денежным и физическим), причем 
в каждой из эти групп должны быть представлены те же менее эффективные трансфертные и более эффективные товарообменные разновидности, т.е. традиционные и альтернативные финансы. Следует отметить, что раньше нами также рассматривались трудовые системы ресурсообеспечения, например труд стариков, но как товарообменная альтернатива традиционному пенсионному обеспечению в старости. При рассмотрении же систем ресурсообеспечения применительно к видам передаваемых ресурсов требуется уже выделение трансфертных и товарообменных альтернатив внутри систем обеспечения разными видами производственных ресурсов, в данной работе - среди систем обеспечения ресурсом «труд».

Трансфертным типом системы обеспечения трудом выступает передача труда его получателю по цене, близкой к прожиточному минимуму, но при этом с лица, передающего труд, снимаются обязанности по обеспечению его рационального использования в интересах получателя труда, труд переходит под почти полное управление получателя труда на всем его протяжении, который сам обеспечивает рациональное использование труда для достижения своих целей. Очевидно, что к этому типу относятся варианты рабского труда с соответствующим содержанием последнего. К нему относятся и варианты вольнонаемного труда, прежде всего тот, когда обязанность обеспечивать рациональное использование передаваемого труда работник снимает с себя по причине его управленческой лени (пассивная лень), и тот, когда работник принципиально не желает управлять своим трудом на благо трудополучателя по причине низкой платы за труд (активная лень). При этом работник исходит из того, что получатель труда, уплачивая ему за труд минимальную цену, не только сам обязан обеспечить эффективное использование труда работника в соответствии со своими целями (соответствующим образом организовать процесс труда, контролировать и корректировать его), но и должен проявлять существенную заботу о самом работнике, например обеспечивать его средствами существования в периоды болезни и временного отсутствия потребности в труде работника, в старости. Эта забота получила название социальных гарантий, предоставляемых работнику работодателем (в состав которых входят и гарантии минимальных выплат за труд), делящихся в настоящее время на предусмотренные законодательством и на устанавливаемые дополнительно самими работодателями с целью создания у себя привлекательных условий труда [7]. Заметим, что, если из вольнонаемных трансфертных трудоотношений исключить пункты, гарантирующие наем и увольнение работников по собственному желанию, то фактически они будут выступать трудоотношениями рабства. Так что трансфертное обеспечение вольнонаемным трудом можно назвать добровольным рабством.

Товарообменным типом системы обеспечения ресурсом «труд» является передача труда его получателю по цене продукта труда, значительно более высокой, чем прожиточный минимум, но это предполагает самостоятельное управление работником своим трудом в интересах получателя труда и, соответственно, передачу получателю труда нужного ему конечного продукта труда. При этом работник, получая от получателя труда полную его оплату, т.е. значительные деньги, не рассчитывает и на то, что получатель труда будет нести перед ним какую-то социальную ответственность. Таким образом, более высокая цена труда в товарообменном трудовом контракте обусловлена двумя обстоятельствами. Одна надбавка выплачивается за собственное управление работником своим трудом, обеспечивающее его максимально эффективное использование. Другая надбавка выплачивается за то, что работник не требует от получателя труда социальных гарантий.

В соответствии с теорией альтернативных финансов, товарообменный вариант системы ресурсообеспечения является более эффективным (более экономичным, доступным и безопасным), чем ее трансфертный вариант, как для ресурсодателя, так и для ресурсополучателя, что распространяется и на обеспечение трудом. Товаробменный вариант труда является более эффективным для работника, прежде всего, потому, что является более экономичным способом извлечения трудового дохода. Имеется в виду, что, несмотря на то, что в этом случае работник затрачивает дополнительные силы на управление своим трудом с целью получения его продукта, нужного получателю труда, все же общие трудозатраты на единицу получаемого дохода оказываются существенно меньшими, чем в случае пассивной передачи труда его получателю.

Товарообменный вариант также является более доступным для работника, так как работ- 
ник, передающий свой труд в виде его конечного продукта, интересующего получателя труда, быстрее найдет работу, если захочет трудоустроиться (поскольку этот вариант обеспечения трудом является более эффективным и для получателя труда - см. ниже). По той же причине товарообменный вариант является и менее опасным для работника, имея в виду, прежде всего, потерю им дохода в случае, когда получатель труда перестает нуждаться в его труде. Так, имеющий возможность быстро найти новую работу работник, продающий конечные результаты труда, хотя на период между двумя работами и полностью теряет свой доход, но быстро его восстанавливает, тогда как пассивный работник, хотя и сохраняет свой доход в урезанном виде за счет социальных гарантий, например, получает 2/3 оклада в период простоя, разумеется, если не оказался отправленным в неоплачиваемый отпуск [3], может длительное время ожидать его восстановления на прежнем месте работы.

Товарообменный вариант обеспечения трудом является более эффективным и для получателя труда. Он является, прежде всего, более экономичным способом извлечения его продукта. Имеется в виду, что, несмотря на то, что плата за труд в этом случае существенно увеличивается, все же удельные затраты на единицу продукта труда существенно сокращаются за счет, как экономии на затратах по управлению пассивным трудом, так и повышения полезности получаемого конечного продукта труда (вещи, услуги), так как внешнее управление трудом, разумеется, при прочих равных условиях, является менее эффективным, чем внутреннее (осуществляемое самим работником).

Товарообменный вариант является и более доступным для получателя труда, так как желающих продать результат труда больше, чем желающих продать его функцию (поскольку этот вариант обеспечения трудом является более эффективным и для работника - см. выше). Он является и менее опасным для получателя труда, так как в случае исчезновения у него потребности в соответствующем труде он не несет издержек, связанных с исполнением предоставленных пассивным работникам социальных гарантий, например может мгновенно расторгнуть договор с работником без выплаты ему выходного пособия.

Большая эффективность товарообменного труда по сравнению с трансфертным в масшта- бах общества обусловлена как его большей экономичностью (меньшими затратами на единицу трудового дохода или продукта труда), так и большей мобильностью (способностью быстро менять работодателей или находить новую работу) первого по сравнению со вторым.

Подтверждением наличия у вольнонаемного труда трансфертной и товарообменной альтернатив является выделение в юридической науке и практике двух типов договоров, регулирующих отношения работодателей (получателей труда) и наемных работников - трудового договора и договора гражданско-правового характера (имеющего ряд разновидностей: договор подряда, договор возмездного оказания услуг, договор поручения и т.д. [6]), а также альтернативный характер их заключения. Не сложно обнаружить, что основные различия между этими договорами, выделяемые экспертами, вытекают из основных различий между трансфертным и товарообменным трудом, ясных из их определений, данных нами выше. Первым различием между трансфертным и товарообменным трудом, кроме значительно более высокой оплаты второго по сравнению с первым, является противоположное участие в управлении им работника и работодателя. Трансфертный труд - труд, при котором с работника снимаются обязанности по обеспечению его рационального использования в интересах работодателя, в связи с чем этот труд передается под почти полное управление получателя труда на всем его протяжении, и работодатель сам обеспечивает рациональное использование получаемого труда для достижения своих целей. Товарообменный труд - труд, предполагающий самостоятельное управление работником своим трудом в интересах получателя труда и, соответственно, передачу получателю труда только нужного ему конечного продукта труда.

Этим различиям соответствуют такие выделяемые экспертами различия между трудовым договором и договором ГПХ [2]:

1. По трудовому договору получатель заказывает процесс труда, а по гражданскоправовому - его результат (продукт). Это объясняется тем, что трансфертный труд постоянно находится под управлением получателя труда, а товарообменный - лишь при сдаче работодателю продукта труда.

2. Трудовой договор предполагает работу работника в определенной должности с выпол- 
нением всех текущих указаний работодателя, а договор ГПХ - выполнение задания работодателя, известного на момент заключения договора. Это вытекает из того, что трансфертный труд управляется работодателем путем выдачи работнику операционных инструкций, рабочих правил, должностных обязанностей, что и означает работу в определенной должности, и отдачи ему указаний, а трансфертный - путем описания его конечного результата, интересующего работодателя.

3. По трудовому договору работник получает заработную плату, выплачиваемую 2 раза в месяц, а по договору ГПХ - вознаграждение, которое может выплачиваться в форме предоплаты, поэтапной оплаты, оплаты после сдачи работ. Ритмичный характер оплаты труда по трудовому договору объясняется тем, что при трансфертном труде работник сдает (на проверку) свой труд работодателю постоянно, так как его результативность постоянно контролируется работодателем, поскольку он сам непосредственно управляет получаемым трудом в своих интересах. При товарообменном труде работник сдает свой труд работодателю лишь путем сдачи его конечного продукта или иногда промежуточных результатов его изготовления, что и обусловливает особенности расчета за труд по договору ГПХ.

4. По трудовому договору работник исполняет правила трудового распорядка работодателя, а по договору ГПХ работник сам устанавливает свой трудовой распорядок (распределение труда во времени). Это объясняется тем, что трансфертным трудом постоянно управляет работодатель, в связи с чем этот труд и должен осуществляться во время, которое устанавливает для управления им работодатель, а так как товарообменный труд управляется работником самостоятельно, работодателю нет нужды требовать его исполнения во время, когда он осуществляет свою (управленческую) деятельность.

5. Исполняя работу по трудовому договору, работник не может привлечь к ее исполнению третьих лиц, а исполняя ее по договору ГПХ может. Это объясняется тем, что при трансфертном труде способ исполнения работы, поручаемой работнику, в том числе участие в ней других лиц, определяет получатель труда, а при товарообменном - сам работник.

Из определений трансфертного и товарообменного труда видно, что первый отличается от второго еще и тем, что требует в обмен на труд также предоставления работнику социальных гарантий. Среди различий между трудовым договором и договором ГПХ эксперты обязательно указывают такое различие между ними, как то, что договор ГПХ, в отличие от трудового договора, не предусматривает социальных гарантий работнику [2].

При этом одна и та же по конечному продукту работа может осуществляться как по трудовому договору, так и по договору ГПХ. Об этом говорит обилие литературы, посвященной плюсам и минусам оформления трудовых отношений трудовыми договорами и договорами ГПХ, правильному оформлению трудовых отношений по договорам ГПХ, беспроблемному переводу сотрудников с трудовых договоров на договора ГПХ, причем часто это те же источники, в которых рассматриваются различия между двумя типами договоров. Так, в одном из них также отмечается, что компания вправе сама определять, какой тип договора использовать для оформления отношений с наемными работниками, но должна следить за тем, чтобы тип договора соответствовал реальным трудовым отношениям, что для безболезненного перевода штатных сотрудников на договора ГПХ нужно вначале правильно расторгнуть трудовые договоры (работодатель должен уведомить сотрудника о расторжении с ним трудового договора по соглашению сторон, на которое тот должен дать письменное согласие, заключить соглашение о расторжении с сотрудником с оформлением соответствующего приказа, выплатить всю причитающуюся сотруднику зарплату и компенсации), затем заключить с сотрудником договор подряда, возмездного оказания услуг или агентский договор, в котором нужно прописать вместо трудовой функции и должности вид исполняемой работы, а вместо регулярной оплаты труда указать сроки выплаты вознаграждений за сделанную работу [2].

Очевидно, что концепции трансфертного и товарообменного труда передают сущность трудовых отношений, оформляемых трудовыми договорами и договорами ГПХ, если под сущностью предмета понимать его определяющую сторону, но скрытую от внешнего наблюдения. Представляется, что сущностью отношений по трудовому договору является управление трудом работника для достижения целей работодателя самим работодателем, а трудовых отношений по 
договору ГПХ - управление трудом работника в интересах работодателя самим работником, поскольку именно эти различия в управлении двумя видами труда определяют различия в благах, получаемых работниками (низкую плату за труд, равную стоимости его содержания, и такие же дешевые социальные гарантии или полную плату за труд, равную стоимости его продукта). Еще более глубокой сущностью трудовых отношений по трудовому договору и по договору ГПХ является наличие в первом случае у работника управленческой лени, а во втором - ее отсутствие.

Остальные статьи цикла, посвященного трансфертному и товарообменному труду, опубликованные в данном номере журнала «Экономические науки» (авторы: К. Н. Лебедев, Ю.И. Будович) посвящены вопросам вытеснения трансфертного труда товарообменным трудом, происходящего в современном мире.

\section{Библиографический список}

1. Будович Ю.И., Лебедев К. Н. Место финансов в современной экономике (Экономика без финансов) / под ред. К. Н. Лебедева. - Краснодар: Издательство НИИ экономики ЮФО, 2020. 186 с.

2. Гражданско-правовой договор / Открытие. Академия бизнеса. 16.11.2020. URL: https://academyopen.ru/ journal/391 (дата обращения: 22.09.2021).

3. Если бизнес страдает от кризиса: как быть с персоналом / Клерк. 01.04.2020. URL: https://www.klerk.ru/buh/ articles/497740/ (дата обращения: 23.09.2020).

4. Крюков Д. 10 причин человеческой лени и бездействия / Психологи на b17.ru. URL: https://www.b17.ru/ article/10_prichin_chelovecheskoj_leni/ (дата обращения: 30.10.2021).

5. Лебедев К. Н. Экономика без финансов // Вопросы экономики и права. 2018. № 6 (120). С. 45-53.

6. Покшан Д. Особенности заключения гражданско-правового договора в 2021 году / Блог кадровика. URL: https://blogkadrovika.ru/dogovor-gpx/ (дата обращения: 22.09.2021).

7. Сигаева Е. Какие есть социальные гарантии у работников / Налог-налог.pу. 07.04.2021. URL: https://nalognalog.ru/lgoty_garantii_i_kompensacii/kakie_est_socialnye_garantii_u_rabotnikov/(дата обращения: 11.10.2021). 